\title{
Diacronie
}

Studi di Storia Contemporanea

$\mathrm{N}^{\circ} 15,3$ | 2013

Spazi, percorsi e memorie

\section{La Iglesia argentina en la historia reciente (1983-1989)}

\section{Mariano Fabris}

\section{(2) OpenEdition}

Journals

\section{Edición electrónica}

URL: http://journals.openedition.org/diacronie/484

DOI: 10.4000/diacronie.484

ISSN: 2038-0925

\section{Editor}

Association culturelle Diacronie

\section{Referencia electrónica}

Mariano Fabris, « La Iglesia argentina en la historia reciente (1983-1989) », Diacronie [En línea], № 15, 3 | 2013, documento 7, Puesto en línea el 01 octubre 2013, consultado el 03 mayo 2019. URL : http:// journals.openedition.org/diacronie/484; DOI : 10.4000/diacronie.484 


\title{
Diacronie
}

\section{La Iglesia Argentina en la historia reciente (1983-1989)}

\author{
Mariano FABRIS*
}

Con la elección de Jorge Bergoglio como nuevo Papa, la Iglesia argentina pasó a ocupar un lugar de mayor consideración dentro del mundo católico. En este artículo nos preguntamos por la trayectoria de la institución en la que se formó y de la que llegó a ser su máxima figura. Entendemos que el período posterior a la última dictadura militar (1976-1983) y que coincide con el gobierno de Raúl Alfonsín (19831989) resulta fundamental para comprender el proceso de recomposición institucional de una Iglesia fuertemente cuestionada por sus vínculos con el gobierno

\section{Introducción ${ }^{1}$}

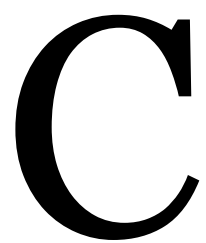

on la elección de Jorge Bergoglio como nuevo Papa, la Iglesia argentina pasó a ocupar un lugar de mayor consideración dentro del mundo católico. Si bien nuestra intención no es detenernos en la trayectoria de Francisco I, nos preguntamos por la trayectoria de la institución en la que se formó y de la que llegó a ser su máxima figura. Entendemos que el período posterior a la última dictadura militar (1976-1983) y que coincide con el gobierno de Raúl Alfonsín (19831989) resulta fundamental para comprender el proceso de recomposición institucional de una Iglesia fuertemente cuestionada por sus vínculos con el gobierno militar. Este artículo trata sobre esos años críticos cruzados por desafíos y muy alejados del espíritu triunfalista dominante en la actualidad.

\footnotetext{
${ }^{1}$ Este artículo retoma brevemente algunos recorridos seguidos por el autor en su tesis doctoral: FABRIS, Mariano La Conferencia Episcopal Argentina en tiempos del retorno democrático, 1983-1989. La participación política del actor eclesiástico. Tesis Doctoral en Historia, UNMdP, Mar del Plata, 2011.
} 
La Iglesia católica se ha mostrado siempre como un actor de muy difícil acceso para los investigadores. Más aun si se trata de su jerarquía y en periodos recientes. Un halo de secreto y hermetismo desalienta a aquellos acostumbrados a abordar actores preocupados e interesados en hacer oír su voz para dejar su marca en la historia. La jerarquía católica no rehúye a la historia; por el contrario, elabora la propia en forma sistemática a través de un relato que la ubica como la representante de la Iglesia en el territorio nacional y como un actor ajeno por completo a la conflictividad política.

Conscientes de estos obstáculos, nuestras investigaciones sobre la Iglesia argentina intentaron sortearlos para lograr comprender de qué forma este esquivo actor se insertó en el contexto político que se abrió con la derrota argentina en la Guerra de Malvinas y, particularmente, de qué manera el Episcopado representó su accionar político en el pasado inmediato, cómo intervino en algunas de las principales cuestiones sociales que, según entendía la Iglesia, estaban bajo su órbita y qué espacios de intermediación ocupó en la configuración política cambiante de los años ochenta².

Abordar estos problemas, implica adentrarse en un terreno prácticamente inexplorado. Las pocas investigaciones disponibles, tendieron a resaltar los aspectos más polémicos de las relaciones entre la Iglesia y el gobierno de Raúl Alfonsín, principal figura de la Unión Cívica Radical en los años ochenta. Hasta el momento, se observó el pensamiento dominante en el Episcopado para evaluar en qué medida era útil a la consolidación de la democracia y se analizaron someramente algunas de las cuestiones más polémicas, como el debate sobre las reformas en la legislación matrimonial o las disputas en torno a la democratización de la cultura3 ${ }^{\text {. Entendemos }}$ que otras cuestiones merecen ser analizadas para lograr un conocimiento más profundo de este proceso. En primer lugar se hace necesario desmitificar la oposición gobiernoIglesia y comenzar a observar las tensiones generadas entre ambos actores y sus relaciones en un marco de competencia pero también de acuerdos. En segundo término, es imprescindible tener en cuenta no sólo del pensamiento dominante en el Episcopado sino también la forma en que éste articuló la participación católica en los debates más importantes del periodo.

Reflexionar sobre la Iglesia argentina nos conduce a preguntarnos por cómo percibían los obispos la presencia del catolicismo en la sociedad y en qué ámbitos se

\footnotetext{
2 FABRIS, Mariano, Iglesia y democracia: avatares de la jerarquía católica en la Argentina post autoritaria, 1983-1989, Rosario, Prohistoria, 2011

3 EZCURRA, Ana María, Iglesia y transición democrática. Ofensiva del neoconservadurismo católico en América Latina, Buenos Aires, Puntosur, 1988; ESQUIVEL, Juan Cruz, Detrás de los muros. La Iglesia católica en tiempos de Alfonsín y Menem (1983-1999), Buenos Aires, UNQUI, 2004; GHIO, José María, La iglesia católica en la política argentina, Buenos Aires, Prometeo, 2007.
} 
manifestaba esa presencia. Creemos que hay un conjunto de cuestiones que desnudan los entramados de relaciones que vinculaban al Episcopado con los demás actores de poder. No sorprende demasiado que el ámbito educativo y el familiar hayan sido los más disputados. El hogar y la escuela siempre fueron entendidos como los principales medios para garantizar la irradiación del mensaje católico en la sociedad. De todas formas, durante la presidencia de Raúl Alfonsín, las disputas en estos ámbitos se reactualizaron a partir del debate sobre el divorcio vincular - aprobado en 1987 - y de la convocatoria a un Congreso Pedagógico para discutir sobre la educación argentina. Asimismo, la idea de modernización que el gobierno buscaba imprimir en la cultura a través de un discurso y de un conjunto de medidas garantistas de la libertad de expresión, despertaron una fuerte reacción entre los católicos más conservadores. Para la mayoría de los obispos lo que estaba en juego eran los valores trascendentales de la Nación y, además, el de su sustrato católico.

El particular contexto político que vivía la Argentina luego de siete años del más feroz gobierno militar (1976-1983) determinó nuevas preocupaciones. La Iglesia participó directa o indirectamente en los debates sobre el pasado reciente que pretendieron definir cómo la sociedad procesaba los traumas heredados y en particular qué hacer con la larga lista de violaciones a los derechos humanos perpetrados por la dictadura militar.

Finalmente, el Episcopado intervino también en las relaciones entre el gobierno y los sindicatos, de las que se constituyó en intermediario y encontró en ese nuevo rol un espacio de acomodamiento institucional en la nueva configuración política, apadrinando el diálogo y la reconciliación entre actores en pugna.

A estas cuestiones nos referiremos sintéticamente en las páginas siguientes para comprender el papel que desempeño la jerarquía católica argentina en la historia reciente del país.

\section{Un esquivo objeto de estudio}

Se hace necesario definir los contornos del objeto de estudio, porque hablar de la Iglesia puede remitir a instituciones, grupos e ideas de notable diversidad. En nuestro caso nos hemos centrado en la Conferencia Episcopal Argentina (CEA) que agrupa al conjunto de obispos. Se trata del órgano principal de la Iglesia católica a nivel local cuyas decisiones resultan determinantes en las orientaciones de la Iglesia en tanto institución con específicos intereses políticos. Claro está, esas orientaciones no ignoran 
las relaciones que se producen en el interior del catolicismo entre esa jerarquía, el clero y el laicado.

La estructura colegiada de la CEA constituye la máxima expresión de la búsqueda de control y concertación. Cuando esta búsqueda es exitosa, ofrece una imagen de unidad que resulta determinante para consolidar su presencia social e incidir en la vida política del país. Generalmente, esa imagen de unidad que construyen los obispos va acompañada por una negación de sus ambiciones de poder temporal que otorga credibilidad ante la sociedad al mensaje y las prácticas "religiosas". Es por esta razón que la búsqueda de la jerarquía eclesiástica por mejorar su posición en las relaciones de poder con los demás actores tiene como elemento determinante "el doble sentido y el eufemismo".4

A partir de estas consideraciones, entendemos que la CEA es un actor político-social que se inserta en configuraciones políticas cuyos equilibrios de poder son sumamente inestables. A través de las relaciones que establece, afianza su representación de la Iglesia, aumenta la coordinación entre las diferentes diócesis y logra una mejor inserción social. Así, la CEA canaliza y consolida la presencia del catolicismo en realidades sociales sumamente cambiantes.

\section{Las disputas por el pasado}

Hay razones que permiten sostener que la CEA no podía permanecer al margen de las disputas por la construcción de una memoria social de un pasado reciente cruzado por la violencia política y el terrorismo de Estado. En esta dirección, no se puede ignorar que tradicionalmente, y en particular durante la última dictadura, el catolicismo fue destacado por los militares argentinos como una fuente de inspiración. Durante la larga noche del autoproclamado "Proceso de Reorganización Nacional" los obispos disfrutaron de un status privilegiado y se mostraron junto a las autoridades militares en momentos en los que otros actores eran silenciados y reprimidos. Estas circunstancias no pasaron desapercibidas y dieron sustento a una imagen de complicidad con las FFAA.

Desde el final de la guerra de Malvinas y sobre todo tras el retorno democrático, el pasado se volvió un terreno de disputa en el cual estaban en juego las posiciones de los actores en la configuración política. Al calor del debate por la cuestión de los derechos

\footnotetext{
4 BOURDIEU, Pierre, SAINT-MARTIN, Monique de, La Sagrada Familia. El episcopado francés en el campo de poder in BOURDIEU, Pierre, La eficacia simbólica. Religión y política, Buenos Aires, Biblos, 2009, p. 151.
} 
humanos, la volatilidad de las opiniones y las posiciones de los actores políticos y de los medios de comunicación, que poco antes evitaban hablar de los crímenes, permitieron que afloraran otras voces, antes silenciadas o sistemáticamente ignoradas, que tuvieron algo que decir sobre la Iglesia y no fueron precisamente elogios.

Respecto a esto, entendemos que lo interesante es analizar cómo operaban dichas interpretaciones en las disputas del presente. Así, se puede observar que el Episcopado reaccionó rápidamente y elaboró una interpretación institucional de lo sucedido en los años setenta que inscribió su accionar en un marco temporal que excedía el de la última dictadura, que rechazó la violencia «de uno y otro lado» y que presentó a la Iglesia como ajena y por encima del conflicto político. La interpretación episcopal tuvo un parecido con la llamada «teoría de los dos demonios», sostenida por el gobierno democrático a partir de 1983, y que consistió en una interpretación que se construía desde una pretendida neutralidad y que rechazaba tanto a la violencia política propia de los grupos guerrilleros, como a la represión militar. No faltaron obispos que plantearan una lectura alternativa, ya fuera encolumnándose junto a los militares en la defensa de la experiencia dictatorial o bien enfrentándolos abiertamente a través de una crítica de la metodología represiva, de su política económica y de sus alineamientos internacionales. Si bien fueron minoritarias, la relevancia social que tuvieron estas últimas interpretaciones fue destacada. Las intervenciones de obispos como Miguel Hesayne, Jorge Novak o Jaime De Nevares fueron significativas y gozaron de amplia cobertura en los medios, aunque siempre aparecieron como voces aisladas en una jerarquía que les era adversa. En sentido contrario, la posición de los prelados que defendieron en forma militante a la dictadura, también minoritaria, fue presentada como el ejemplo más representativo de la complicidad de la institución.

Esta diferente consideración se explica por dos motivos. Habría que reconocer que para los grupos políticos e intelectuales - tanto en el interior de los partidos mayoritarios como en agrupaciones menores- que se definían en oposición a la Iglesia, la complicidad institucional encarnada por obispos como Antonio Plaza o José Medina resultó importante en las disputas que guiaron los reacomodamientos en la política post Malvinas ${ }^{5}$ Hubo también otra razón más profunda. La mayoría de los obispos no

5 En abril de 1982 el presidente de facto general Leopoldo Galtieri decidió llevar a cabo el desembarco en las islas Malvinas, ocupadas por Inglaterra desde el siglo XIX, para dar un nuevo impulso a un declinante gobierno militar. La guerra formó parte de una estrategia tendiente a frenar una tenue apertura política que se venía produciendo desde 1981, realineando al conjunto de la población tras la gesta nacionalista. Un triunfo en la guerra hubiera significado la legitimación de una dictadura en retroceso. Sin embargo, la derrota llevó a la profundización de la crisis y abrió el camino para el retorno de la democracia, NOVARO, Marcos, PALERMO, Vicente, La dictadura militar, 1976-1983, Buenos. Aires, Paidos, 2003. 
realizó una defensa militante de la dictadura y mostró cierta dosis de pragmatismo. Durante el Proceso la CEA, orientada por su presidente Raúl Primatesta, había transitado un camino desde la legitimación del golpe de Estado al reclamo por la reinstitucionalización del país (un movimiento igual al realizado por la sociedad argentina en general). Más allá de ese tránsito, siempre pervivió entre los miembros del Episcopado una matriz ideológica que desnudó los estrechos vínculos establecidos entre la Iglesia y las FFAA. En efecto, la visión de la sociedad definida por un único conjunto de valores, entre los cuales se destacaba el cristianismo impreso desde la colonización y custodiado por la Iglesia y las FFAA, permaneció arraigada en el pensamiento de numerosos obispos.

$\mathrm{Al}$ sostener esta pervivencia no queremos caer en el anacronismo de pensar que en el contexto político argentino posterior a 1983 los prelados propiciaban una reedición de la alianza entre la «cruz y la espada» que selló los vínculos entre la Iglesia y las FFAA en la década de 1930. Luego de la experiencia dictatorial y tras el desprestigio de las FFAA, la mayoría de ellos reconoció que esa era una alianza imposible, aun cuando recuperaran elementos de la concepción unívoca de la sociedad que le había dado sustento. Por lo tanto, la imagen de complicidad con los militares fue resultado del efectivo compromiso de algunos obispos y de la estrecha imbricación entre los discursos castrenses y las posiciones asumidas por importantes figuras de la jerarquía católica.

La actitud de los obispos frente a los juicios a los militares implicados en la violación de los derechos humanos no mejoró la valoración social del papel de la Iglesia en el pasado reciente. La CEA elaboró una "doctrina" centrada en las ideas de reconciliación y perdón con la intención de dar un cierre a la cuestión y la puso a disposición de la dirigencia política. Ambas ideas tenían una larga tradición en la doctrina cristiana y por ello formaron parte del horizonte conjeturado por todos los obispos. Sin embargo, el significado que le otorgó cada uno fue diferente. Unos pocos refirieron a la reconciliación como una aspiración de toda sociedad que debía ser construida sobre la verdad y el reconocimiento de los yerros de cada uno, nunca como una alternativa a la justicia. A diferencia de ellos, la mayoría elaboró una interpretación que convirtió a la reconciliación en una herramienta política destinada a restituir la unidad de la nación luego de la dictadura, a través de la clausura de los procesos judiciales seguidos a los militares represores. La insistencia de los obispos en esta solución para el procesamiento judicial del pasado estuvo en contradicción con el extendido apoyo social que tuvieron los juicios. 


\section{La jerarquía católica y el "destape"}

Se podría decir que las expresiones artísticas de consumo masivo y los medios de comunicación reflejaron velozmente y con gran intensidad el impacto de los cambios políticos que condujeron al retorno de la democracia. Para los obispos la expresión más evidente de ese impacto fue el llamado "destape", que suponía temas y formas de abordarlos centradas en la cuestión sexual que, marginados hasta entonces, avanzaban como una avalancha incontrolable.

El contraste con el período dictatorial no podía ser mayor. El gobierno militar había despertado entusiasmo en los obispos cuando planteaba la defensa de los valores religiosos y el respeto a un modo de ser cristiano que se asumía amenazado. Las promesas no cumplieron las expectativas y no dieron forma a una sociedad armónicamente ordenada según esos valores. Las inconsistencias y contradicciones del gobierno militar en materia de control de las expresiones culturales y los medios de comunicación se volvieron dramáticas para los obispos cuando luego de la Guerra de Malvinas nadie estuvo dispuesto a respetarlas.

Este tránsito de un régimen militar que imaginaba a la sociedad desde la unanimidad de los valores occidentales y cristianos a uno democrático asentado en el pluralismo no fue sencillo para la mayoría de los obispos y el laicado más conservador. Lo vivieron como una derrota y lo procesaron a través de la denuncia de una conspiración orquestada para modificar los rasgos culturales de la nación. Este argumento tuvo eco en los documentos de la CEA y fue explícitamente presentado por obispos como Emilio Ogñenovich, Antonio Quarracino o Ítalo Di Stefano. Este último se convirtió en un verdadero paladín de la defensa de los valores amenazados y, en varias oportunidades, ello lo llevó a abiertos enfrentamientos con las autoridades nacionales.

\section{La aprobación del divorcio: de la confrontación al acuerdo}

En la década de 1980 la Argentina era uno de los pocos países que no contaba en su legislación con el divorcio vincular. Por ello, en el ámbito familiar se auguraba una fuerte disputa entre las nuevas autoridades y la Iglesia siempre opuesta a cualquier modificación del régimen matrimonial vigente. La aprobación del divorcio era una posibilidad cierta si se tiene en cuenta que proyectos en esa dirección se habían presentado en casi todos los períodos democráticos desde principios de siglo XX. Con el 
retorno de la democracia los primeros en asumir esa posibilidad -por lo menos públicamente- fueron los obispos, quienes ya desde la campaña electoral pusieron en aviso al futuro gobierno sobre la actitud defensiva que tomarían si se trataba de modificar la legislación familiar.

La cautela con que los políticos trataron la cuestión durante esos meses de campaña electoral fue abandonada rápidamente una vez que se hizo efectivo el cambio de gobierno y varios proyectos de divorcio fueron presentados en el Congreso. Se puede decir que la CEA hizo todo lo posible por reeditar la larga saga de enfrentamientos que precedían la discusión. A monseñor Ogñenovich se le otorgó hasta finales de 1986 la libertad necesaria para liderar una ofensiva contra el divorcio con tono de "cruzada”. El obispo cumplió la tarea con creces: a través de discursos apocalípticos que presagiaban el fin de la nación, pero sobre todo a través de una densa red de instituciones, obtuvo el compromiso de la mayoría de los obispos y una parte del laicado para llevar el debate a las calles. Los resultados fueron distintos de los esperados. Nadie recogió el desafío de Ogñenovich y la calle no se convirtió en ese terreno de debate imaginado, varios obispos rechazaron la metodología planteada e incluso algunos como Justo Laguna, Hesayne o De Nevares discreparon abiertamente. En definitiva, el apoyo de los católicos a la posición de la Iglesia fue menor que el esperado porque formaban parte de una sociedad en la cual las separaciones eran una realidad. En las diócesis donde se llevaron adelante manifestaciones públicas, la respuesta sólo vino de los grupos laicales más comprometidos y, en particular, del alumnado de los colegios privados católicos.

Ante la magnitud de la campaña para enfrentar al divorcio, su aprobación en la Cámara de Diputados fue traducida como una derrota de la jerarquía católica. Esa derrota y las disidencias internas que había disparado fueron procesadas a través de un cambio en la actitud frente al tratamiento en el Senado. Se dejó de lado la ofensiva encabezada por Ogñenovich y a partir de negociaciones políticas con el partido de gobierno (UCR) y el peronismo ortodoxo se logró posponer el debate del divorcio para después de la visita del Papa, Juan Pablo II, programada para abril de 1987. Con esta reorientación, bajaron las tensiones entre los obispos y se logró restituir la imagen pública de unidad. Luego de la masiva movilización que recibió y acompañó al Papa en cada ciudad que visitó en el país, la jerarquía católica pudo superar aquella sensación de derrota del año anterior. El divorcio fue aprobado por el Senado en junio de 1987 sin mayores sobresaltos. 


\section{La participación de la Iglesia en el debate educativo}

Desde la óptica del gobierno radical encabezado por Raúl Alfonsín la sucesión de golpes de Estado que se había producido desde 1930 revelaba el escaso arraigo social de los valores democráticos. En consecuencia, se planteó la necesidad de reflexionar sobre la responsabilidad que le cabía a la educación en la primacía de una cultura política autoritaria. La principal propuesta en esta dirección fue la convocatoria a un Congreso Pedagógico Nacional (en adelante CPN) que debía, aún sin ser vinculante, orientar la política educativa de la nueva etapa refundando el sistema educativo en consonancia con las ideas democráticas. Contrariamente a lo que ocurrió con el debate del divorcio, la Iglesia fue la gran protagonista del Congreso Pedagógico Nacional, prevaleció en la mayoría de las asambleas realizadas en las provincias y la Capital Federal y logró la aprobación de muchos de los principios que defendió en el encuentro final llevado a cabo en la provincia de Córdoba. Claro que el recorrido no fue sencillo. Inicialmente, hubo sectores católicos que recibieron la convocatoria con desconfianza. Discutir la educación, en un contexto de extendida crítica al pasado reciente, en paralelo al debate por el divorcio y a través de un evento que se legitimaba invocando el modelo de educación laica puesto en vigencia en las últimas décadas del siglo XIX, no podía despertar más que reticencias en el catolicismo. Sin embargo, desde la jerarquía hubo un fuerte compromiso para superarlas y participar activamente en la discusión. Muchas veces la motivación se logró despertando los temores de los católicos a través de mensajes que anunciaban que la educación privada confesional estaba en peligro. En concreto, el compromiso con la convocatoria demostrado por los católicos fue superior al de cualquier otro grupo.

Si se acepta que una condición esencial para que un congreso funcione es que haya espacio para el debate respetuoso de la pluralidad de ideas, hay que reconocer que en este aspecto no hubo demasiado éxito. En la mayoría de los casos, los encuentros del CPN se parecieron a las asambleas de los sindicatos o de los partidos políticos. Estuvieron dominadas por denuncias de fraude y, en algún caso, de violencia, y se redujeron a contiendas electorales con escaso margen para la discusión o el intercambio de ideas. Ante el éxito de la Iglesia y el fracaso de los partidos políticos, es posible afirmar que el CPN surgió al calor de la euforia que acompañó a la asunción de Alfonsín y fue fruto del espíritu modernizador de los funcionarios radicales pero condensó en su devenir los límites de la promesa democrática. 


\section{La jerarquía católica, la situación económica y los vínculos con el movimiento obrero organizado}

Posiblemente no hay una imagen que sintetice mejor la promesa democrática que encarnó Raúl Alfonsín, que el rezo laico del y la afirmación de que con la democracia "se come, se educa y se cura". ${ }^{6}$ Bastó poco más de un año de gobierno para que esa confianza se mostrara insuficiente para dar solución a la crisis económica que atravesaba el país a la salida de la dictadura; había llegado el momento de la "economía de guerra". La CEA no fue partícipe del clima de optimismo inicial y recordó en repetidas oportunidades que la democracia sólo era posible con justicia social. Desde este llamado de atención, los obispos asumieron un rol activo en el contexto de crisis económica interviniendo en las disputas entre el gobierno y el movimiento obrero organizado.

Ese rol activo del actor eclesiástico tenía antecedentes en el pasado reciente. Desde finales de los años setenta algunos obispos venían propiciando un acercamiento de la Iglesia a los sindicalistas contando para ello con un tímido acompañamiento institucional. Esta vinculación se expresó a través del respaldo a los reclamos obreros frente al gobierno dictatorial. Luego, ya en el contexto de la debacle militar, la CEA siguió estrechando lazos con el sindicalismo. A través del "servicio de reconciliación", se ofreció como intermediaria en las disputas que comprometían al gobierno y los sindicatos desde una pretendida posición prescindente. Si bien la intermediación no ofreció resultados positivos, la Iglesia obtuvo sus mayores logros, ya que siguió participando de la configuración política emergente y fue legitimada por el resto de los

\footnotetext{
${ }^{6}$ Como una forma de hacer evidente el rechazo a la violencia, el autoritarismo y el escaso apego a la legalidad que caracterizaban la vida política argentina, Alfonsín interpeló a la ciudadanía con discursos que incluían el recitado del Preámbulo de la Constitución Nacional. En uno de los discursos más recordados sostuvo: «Vamos hacia el nuevo rumbo, con la nueva marcha, con la nueva lealtad, hacia el futuro de los argentinos. Una marcha presidida por un profundo sentido moral, por un profundo sentido patriótico, para concretar nada más y nada menos que los objetivos del Preámbulo de la Constitución Nacional de los Argentinos, que yo les pido a todos que lo vayamos repitiendo como si fuera un compromiso al mismo tiempo que un rezo laico y una oración patriótica que ya empezamos a cantar, porque esto significa que vamos dejando atrás la decadencia argentina. Estamos en una marcha nueva para constituir la unión nacional, afianzar la justicia, consolidar la paz interior, proveer a la defensa común, promover al bienestar general, y asegurar los beneficios de la libertad para nosotros, para nuestra posteridad y para todos los hombres del mundo que deseen habitar el suelo argentino», Discurso de Raúl Alfonsín en el Estadio de Ferrocarril Oeste, 30 de septiembre 1983. El resaltado es nuestro y corresponde al Preámbulo de la Constitución. Para un análisis del alfonsinismo como intento de reformulación de las identidades políticas argentinas ver: ABOY CARLÉS, Gerardo, Las dos fronteras de la democracia argentina. La reformulación de las identidades políticas, de Alfonsín a Menem, Buenos Aires, Homo Sapiens, 2001.
} 
actores. El protagonismo de los obispos sustentado en la intermediación continuó luego de la asunción del gobierno democrático. Los acuerdos alcanzados entre el gobierno y la Confederación General del Trabajo para la normalización sindical fueron alcanzados en una capilla y con un obispo como anfitrión. Además los sindicalistas y los funcionarios gubernamentales participaron conjuntamente en la Semana Social organizada por el Equipo de Pastoral Social del Episcopado (EPS). Estas actividades ratificaron aquel protagonismo de la CEA.

Sin embargo, la elección de Ítalo Di Stefano como presidente del EPS fue la expresión de un endurecimiento de las actitudes episcopales frente al gobierno. La labor de intermediación dejó de ser una prioridad del EPS, que intensificó la cristianización de grupos sindicales y también empresarios. Si bien 1987 fue un año de distensión coronado por el reemplazo de Di Stefano por Laguna -un obispo cercano a Alfonsín y favorable al diálogo con los diferentes actores-, en medio de una crisis económica incontrolable para el gobierno, las tensiones aumentaron exponencialmente. Paradójicamente, debido al acelerado desprestigio del gobierno, la posición opositora que asumieron los obispos no tuvo consecuencias sobre su idealizada imagen de prescindencia.

\section{Algunas consideraciones finales sobre la jerarquía católica y la política durante el retorno democrático}

El recorrido seguido a través de estas cuestiones resultó fundamental para comenzar a construir una comprensión más profunda de las formas de participación política de un actor político-social como lo es el Episcopado. Consideramos que la jerarquía católica busca consolidar su presencia social mejorando su posición relativa en las relaciones de poder que mantiene con otros actores, en especial el gobierno. El éxito en esta empresa depende, en buena medida, de un enmascaramiento de sus ambiciones políticas. Una imagen de prescindencia política refuerza la posición de la Iglesia. Las intervenciones de los obispos, a través de documentos colectivos, declaraciones y homilías individuales, siempre refieren a fines "trascendentes" para establecer una distancia con el debate político coyuntural. Lo cierto es que argumentando la defensa de los valores nacionales, la reconciliación, la educación de las nuevas generaciones, la familia o la justicia social, la jerarquía católica participó en los debates políticos más importantes del período y fue revirtiendo la imagen negativa con la que emergió de la última dictadura militar. 
Pero el éxito de la CEA en su proyección política necesita también de un marco institucional acorde. La CEA debe afianzar su representatividad del conjunto de los obispos. Es sabido que las Conferencias Episcopales no tienen autoridad formal sobre los obispos aunque llegan a constituirse en un actor clave en el desarrollo e inserción de la Iglesia en cada territorio. Durante la década de 1980, la CEA afianzó su posición como instancia de coordinación de la acción de todos los obispos en las diferentes jurisdicciones eclesiásticas. Esta consolidación de la CEA no significó que reinara la unanimidad entre los obispos. Por el contrario, las diferencias existieron pero nunca pusieron en discusión la legitimidad de la CEA porque en su interior pudieron tener cabida todas las líneas internas presentes en el Episcopado.

El éxito en el logro de estos objetivos debe ser medido teniendo en cuenta que en el contexto político argentino post Malvinas hubo iniciativas gubernamentales que a través de una crítica de la cultura política argentina pusieron en discusión la lógica de intervención política de la Iglesia. En esta dirección, el discurso rupturista del candidato radical que situaba el origen de la crisis argentina en una cultura política autoritaria consolidada desde los años treinta, logró concitar un fuerte respaldo y ofreció las claves para superar los traumas del pasado. Raúl Alfonsín se convirtió así en el narrador legitimado del proceso político y en el principal intérprete de los anhelos de la sociedad. Desde entonces se edificó una imagen que sintetizó su gestión ubicando al gobierno al frente de la lucha contra las corporaciones. Esta imagen - que simplifica el proceso histórico - tuvo sustento mientras se asoció a un conjunto de ideas que implicaba una profunda transformación de la cultura política argentina en dirección a un afianzamiento de los valores democráticos y una redefinición de los espacios reservados a cada actor en la vida política del país. Sin embargo, la intensidad con que fueron defendidas estas ideas fue mermando a la hora de tomar decisiones y enfrentar a través de ellas a las corporaciones. Hemos sostenido que en el espacio político binario que resultó de aquella imagen, parte de la jerarquía católica encontró su lugar representando a la Iglesia como una institución amenazada por defender la vigencia de valores tradicionales.

Junto a aquella imagen rupturista se comprobó la persistencia de prácticas sedimentadas que habían articulado las relaciones entre los actores de poder durante buena parte del siglo XX. Detrás de la ambiciosa reformulación de la cultura política argentina hubo espacio para las negociaciones y acuerdos que, precisamente, formaban parte de esa cultura que se resistía a desaparecer y se presentaban como el camino más rápido para la consolidación de las posiciones de cada actor en la configuración política y como el medio menos costoso para superar sus enfrentamientos. Baste recordar que 
en 1983 el por entonces candidato radical, Raúl Alfonsín, obtuvo un rédito político importante denunciando un pacto militar-sindical que fue fácilmente decodificado como la síntesis de todo lo rechazable de la política argentina. Lejos del deslumbramiento que provoca esa imagen, numerosas investigaciones han demostrado que similares relaciones entre los actores siguieron presentes en la Argentina post dictatorial.

Nosotros, por nuestra parte, hemos subrayado la supervivencia de una configuración política que reservaba un espacio importante para la Iglesia. A medida que el gobierno de Alfonsín encontró obstáculos para el desarrollo de sus políticas más rupturistas, las "viejas prácticas" se volvieron a instalar, adaptadas al nuevo credo democrático. 


\section{* El autor}

Mariano Fabris es Doctor en Historia (Universidad Nacional de Mar del Plata, 2011). Fue Becario postdoctoral en CONICET (2011-2013) y actualmente docente en Historia Social General en la carrera de Sociología (UNMdP) y en Historia Argentina de la carrera de Historia (UNMdP). Se especializa en historia del catolicismo desde el retorno de la democracia en 1983. Ha publicado numerosos artículos en revistas especializadas en Argentina, Chile, México y Brasil y ha colaborado en publicaciones colectivas. Actualmente se encuentra desarrollando un proyecto de investigación sobre la prensa católica en la historia reciente.

URL: < http://www.studistorici.com/progett/autori/\#Fabris >

\section{Per citare questo articolo:}

FABRIS, Mariano, «La Iglesia Argentina en la historia reciente (1983-1989)», Diacronie. Studi di Storia Contemporanea : Spazi, percorsi e memorie, 29/10/2013,

URL:< http://www.studistorici.com/2013/10/29/fabris_numero_15/ >

Diacronie Studi di Storia Contemporanea 3 www.diacronie.it

Risorsa digitale indipendente a carattere storiografico. Uscita trimestrale.

redazione.diacronie@hotmail.it

Comitato di redazione: Marco Abram - Jacopo Bassi - Luca Bufarale - Alessandro Cattunar - Elisa Grandi - Deborah Paci - Fausto Pietrancosta - Matteo Tomasoni - Luca Zuccolo 